\title{
Optimization for Electric Power Load Forecast
}

\author{
I. A. Ethmane ${ }^{1}$, M. Maaroufi ${ }^{2}$, A. K. Mahmoud ${ }^{3}$, A.Yahfdhou ${ }^{4}$ \\ ${ }^{1,3,4}$ Electrical Energy and Control, Mohammedia School of Engineers, Mohammed V University, Morocco \\ ${ }^{2}$ Laboratory of Research Applied to Renewable Energies, Modern University of Nouakchott, Mauritania
}

\begin{tabular}{|c|c|}
\hline Article Info & ABSTRACT \\
\hline Article history: & \multirow{10}{*}{$\begin{array}{l}\text { Load flow studies are one of the most important aspects of power system } \\
\text { planning and operation. The main information obtained from this study } \\
\text { comprises the magnitudes and phase angles of load bus voltages, reactive } \\
\text { powers at generators buses, real and reactive power flow on transmission } \\
\text { lines, other variables being known. To solve the problem of load flow, we } \\
\text { use the iterative method, of Newton-Raphson. Analysis of the found results } \\
\text { using numerical method programmed on the Matlab software and PSS/E } \\
\text { Simulator lead us to seek means of controlling the reactive powers and the } \\
\text { bus voltages of the Nouakchott power grid in } 2030 \text { year. In our case, we } \\
\text { projected the demand forecast at } 2015 \text { to } 2030 \text { years. To solve the growing } \\
\text { demand we injected the power plants in the system firstly and secondly when } \\
\text { the production and energy demand are difficult to match due to lack of } \\
\text { energy infrastructures in 2030.It is proposed to install a FACTS (Flexible } \\
\text { Alternative Current Transmission Systems) system at these buses to } \\
\text { compensate or provide reactive power in order to maintain a better voltage } \\
\text { profile and transmit more power to customers. }\end{array}$} \\
\hline Received May 24, 2018 & \\
\hline Revised Aug 10, 2018 & \\
\hline Accepted Aug 17, 2018 & \\
\hline Keyword: & \\
\hline FACTS & \\
\hline Load flow forecast & \\
\hline MATLAB & \\
\hline Newton-raphson method & \\
\hline Optimization & \\
\hline
\end{tabular}

Copyright $@ 2018$ Institute of Advanced Engineering and Science. All rights reserved.

\section{Corresponding Author:}

\section{A. Ethmane,}

Research Team in Electrical Energy and Control 'RTEEC',

Mohammedia School of Engineers (MSI),

Mohammed V University,

Ibn Sina B.P:765, Rabat, Morocco.

Email: ethmaneisselemarbih1966@gmail.com

\section{INTRODUCTION}

Electric power load forecasting (EPLF) is a vital process in the planning of electricity industry and the operation of electric power systems. The natures of these forecasts are different as well:

a. Short-term forecasts are usually from one hour to one week. They play an important role in the day-today operations of a utility such as unit commitment, economic dispatch and load management.

b. Medium-term forecasts are usually from a few weeks to a few months and even up to a few years. They are necessary in planning fuel procurement, scheduling unit maintenance and energy trading and revenue assessment for the utilities.

c. Long-term electricity demand forecasting is a crucial part in the electric power system planning, tariff regulation and energy trading [12].

d. A long-term forecast is required to be valid from 5 to 25 years. This type of forecast is used to deciding on the system generation and transmission expansion plans.

In this context, it proposed an analysis for the current and evolving production system to satisfy the domestic demand of the $33 \mathrm{kV}$ network. This analysis let use to find, and maintain a voltage profile between 0.95 and $1.05 \mathrm{pu}$, for the electrical network through its modeling by its transfer abilities and by analyzing its simulated results programmed in Matlab and PSS/E Simulator. This modeling is carried out to maintain this voltage profile within the rated limits for the network manager. Another objective is, to propose a methodology for the management and control of power transfer and voltage, in order to make the most 
efficient use of the system more suitable. The FACTS system is a mean of to achieve this function. Several types of FACTS currently exist and the choice of the appropriate device depends largely on the goals to be achieved [10], [8], [11].

For the insertion of FACTS systems, it is sought a stable electrical energy network which is capable even during a disturbance to provide the demand power [3]. This is done while keeping the frequency values constant and close to nominal ones, the alternators rotational speed and the voltage magnitude at the various network buses are kept near the rated values as well.

\section{STRUCTURE OF THE $33 \mathrm{KV}$ LOOP OF NOUAKCHOTT SYSTEM}

The single -line diagram (Figure1.) only represents the $33 \mathrm{KV}$ part of network .The data lines (cables),the generators powers and loads are shown in tables 1 and 2 . The electrical network consist of 9 transmissions lines, 5 generators and 5 loads at bus 2,4,5,6 and 7 of (Figure1.).The active and reactive powers generated are given in MW and MVAr respectively. The voltage of each bus (i) is given in per unit. The load bus is characterized by its active power $\mathrm{P}$ and reactive power $\mathrm{Q}$. Therefore, $(\mathrm{P}, \mathrm{Q})$ are specified, while $(\mathrm{V})$ is to be calculated. In this context, it is proposed for the North bus (1), to be slack bus .Finally, it should also be noted that a bus is numbered (i) and it is connected to $n$ other buses such as those shown in Figure 1.

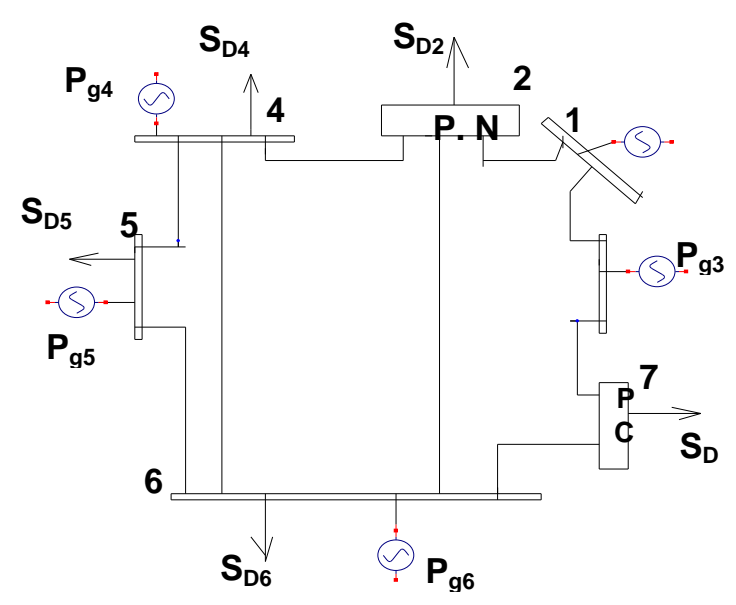

Figure 1. Simplified line diagram; of Nouakchott supply network [12]

It also proposed in Table 1, the active resistances, the line reactances as well as corresponding lengths of each line

\subsection{Cable data}

Table 1. Cable Data of Figure 1

\begin{tabular}{lllllll}
\hline Cable & $\mathrm{i}$ & $\mathrm{k}$ & $\mathrm{R}(\Omega)$ & $\mathrm{X}(\Omega)$ & $\mathrm{U}(\mathrm{KV})$ & $1(\mathrm{~km})$ \\
\hline 1 & 1 & 2 & 0.122 & 0.167 & 33 & 6.27 \\
2 & 1 & 3 & 0.067 & 0.092 & 33 & 3.47 \\
3 & 2 & 4 & 0.027 & 0.037 & 33 & 13.98 \\
4 & 2 & 6 & 0.032 & 0.044 & 33 & 16.8 \\
5 & 3 & 7 & 0.141 & 0.193 & 33 & 7.25 \\
6 & 4 & 5 & 0.17 & 0.232 & 33 & 8.72 \\
7 & 4 & 6 & 0.127 & 0.173 & 33 & 4.51 \\
8 & 5 & 6 & 0.101 & 0.15 & 33 & 5.66 \\
9 & 6 & 7 & 0.232 & 0.31 & 33 & 11.87 \\
\hline
\end{tabular}




\subsection{Generators and electrical loads data}

It is also proposed in Table 2, the initials voltages and their phases. In the analysis of power flow, the generators are modeled as current injectors. In the steady state, a generator is generally controlled so that the active power $\mathrm{P}(\mathrm{MW})$ injected to the bus and the voltage across the generator terminals are kept constant.

Table 2. Data System in 2015 year of Figure 1

\begin{tabular}{ccccccc}
\hline $\mathrm{N}$ & \multicolumn{2}{c}{ Voltage } & \multicolumn{2}{c}{ Generators } & \multicolumn{3}{c}{ Loads } \\
& $\begin{array}{c}\text { Voltage } \\
(\mathrm{pu})\end{array}$ & $\begin{array}{c}\text { Angl. } \\
(\mathrm{deg})\end{array}$ & $\begin{array}{c}\mathrm{P} \\
(\mathrm{MW})\end{array}$ & $\begin{array}{c}\mathrm{Q} \\
(\mathrm{MVAr})\end{array}$ & $\begin{array}{c}\mathrm{P} \\
(\mathrm{MW})\end{array}$ & $\mathrm{P}$ (MVAr) \\
\hline 1 & 1.06 & 0 & 180 & 85.54 & 0 & 0 \\
2 & 1.045 & 0 & 0 & 0 & 5.306 & 2.557 \\
3 & 1 & 0 & 15 & 7.226 & 0 & 0 \\
4 & 1 & 0 & 36 & 17.43 & 2.245 & 1.088 \\
5 & 1 & 0 & 30 & 14.52 & 0.41 & 0.208 \\
6 & 1 & 0 & 93.95 & 45.5 & 1.908 & 0.924 \\
7 & 1 & 0 & 0 & 0 & 2.548 & 1.235 \\
\hline
\end{tabular}

Table 3 shows the generation data at 2015 to 2030 years [12].

Figure 2 shows the injected powers between 2015-2030.

Table 4 shows the 2015-2030 demand forecast data [12].

Table 3. Generation Data at 2015 to 2030 years [12]

\begin{tabular}{lllllll}
\hline \multirow{2}{*}{ Bus } & \multicolumn{2}{c}{} & \multicolumn{2}{c}{ Years } \\
& $\mathrm{P}_{\mathrm{G}}(\mathrm{MW})$ & $\mathrm{Q}_{\mathrm{G}}(\mathrm{MVAr})$ & $\mathrm{P}_{\mathrm{G}}(\mathrm{MW})$ & $\mathrm{Q}_{\mathrm{G}}(\mathrm{MVAr})$ & $\mathrm{P}_{\mathrm{G}}(\mathrm{MW})$ & \multicolumn{2}{c}{ 2025-2030 } \\
\hline 1 & 180 & 87.17 & 270 & 130.68 & 360 & 174.24 \\
2 & - & - & - & - & - & - \\
3 & 15 & 7.26 & 15 & 7.26 & 15 & 7.26 \\
4 & - & - & - & - & - & - \\
5 & 30 & 14.52 & 70 & 33.88 & 60 & 29.4 \\
6 & 137 & 66.346 & 199.75 & 96.679 & 217.25 & 105.149 \\
7 & - & - & 50 & 24.2 & 50 & 24.2 \\
\hline
\end{tabular}

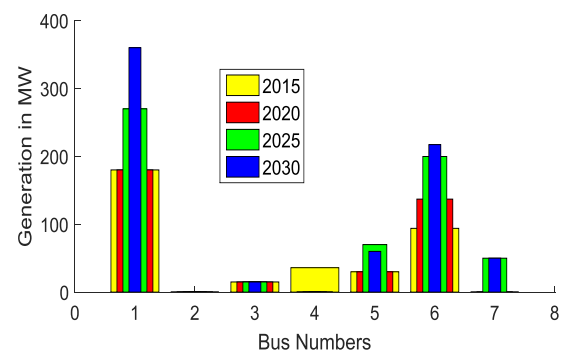

(a)

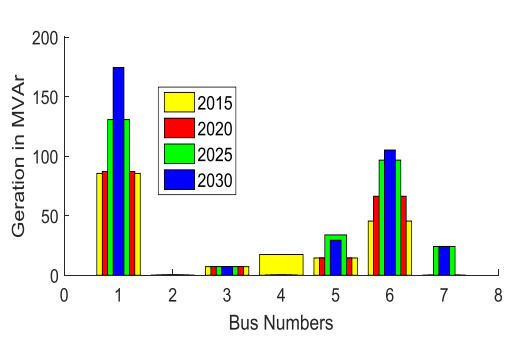

(b)

Figure 2. Injected powers between 2015-2030, (a) active, (b) reactive

Table 4. 2015-2030 Demand Forecast Data [12]

\begin{tabular}{ccccccc}
\hline \multicolumn{1}{c}{ Bus } & \multicolumn{2}{c}{$2015-2020$} & \multicolumn{2}{c}{ Years } & \multicolumn{2}{c}{$2025-2030$} \\
& $\mathrm{P}_{\mathrm{D}}(\mathrm{MW})$ & $\mathrm{Q}_{\mathrm{D}}(\mathrm{MVAr})$ & $\mathrm{P}_{\mathrm{D}}(\mathrm{MW})$ & $\mathrm{Q}_{\mathrm{D}}(\mathrm{MVAr})$ & $\mathrm{P}_{\mathrm{D}}(\mathrm{MW})$ & $\mathrm{Q}_{\mathrm{D}}(\mathrm{MVAr})$ \\
\hline 1 & - & - & - & - & - & - \\
2 & 27.68 & 15.8 & 142.55 & 81.37 & 734.142 & 419.05 \\
3 & - & - & - & - & - & - \\
4 & 11.71 & 6.36 & 60.3 & 32.3 & 310.05 & 166.345 \\
5 & 1.34 & 1.138 & 6.9 & 5.86 & 35.53 & 30.179 \\
6 & 9.4 & 1.17 & 48.41 & 6.02 & 249.31 & 36.82 \\
7 & 13.49 & 7.18 & 69.48 & 7.18 & 357.86 & 190.39 \\
\hline
\end{tabular}


Figure 3 shows the demand forecast between 2015 and 2030 years.

Table 5 shows the admittance matrix of buses in per unit (YBUS).

Table 6 shows the results of NR without STATCOM [3].

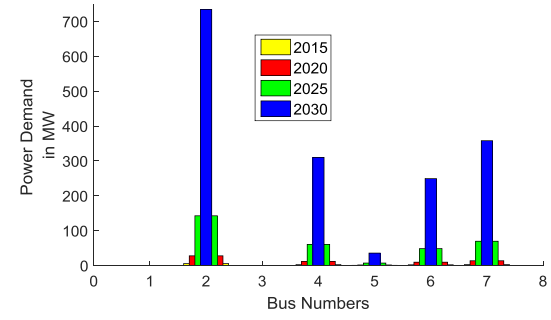

(a)

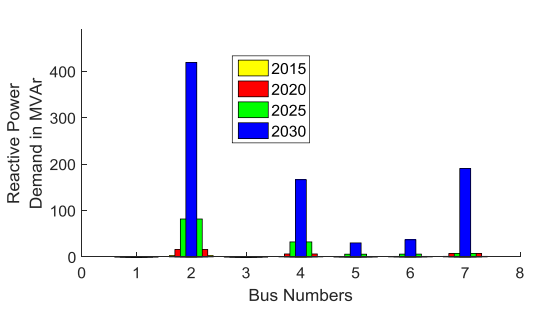

(b)

Figure 3. Demand forecast between 2015 and 2030 years (a) active power, (b) reactive power

Table 5. Admittance Matrix of Buses in Per Unit ( $\left.\mathrm{Y}_{\mathrm{BUS}}\right)$

\begin{tabular}{|c|c|c|c|c|c|c|c|}
\hline $\mathrm{N}$ & 1 & 2 & 3 & 4 & 5 & 6 & 7 \\
\hline 2 & $-56.6-77.9 \mathrm{i}$ & 0 & $87.3-115.8 \mathrm{i}$ & 0 & 0 & 0 & $\begin{array}{c}- \\
30.7+37.9 \mathrm{i}\end{array}$ \\
\hline 3 & 0 & $-14.4+19.8 \mathrm{i}$ & 0 & $39.9-55.4 \mathrm{i}$ & $-22.5+31.5 \mathrm{i}$ & $-2.9+4.1 \mathrm{i}$ & 0 \\
\hline 3 & 0 & 0 & 0 & $-22.5+31.5 \mathrm{i}$ & $57.3-78.8 \mathrm{i}$ & $-34.8+47.2 \mathrm{i}$ & 0 \\
\hline 4 & 0 & $-118.8+163.8 \mathrm{i}$ & 0 & $-02.9+04.1 \mathrm{i}$ & $-34.8+47.2 \mathrm{i}$ & $173.5+22.5 \mathrm{i}$ & $\stackrel{-}{-} 16.9+22.5 \mathrm{i}$ \\
\hline
\end{tabular}

Table 6. Results of NR without STATCOM [3]

\begin{tabular}{llll}
\hline Bus & \multicolumn{1}{c}{ Type } & \multicolumn{1}{c}{ Vpu } & \multicolumn{1}{c}{ Angle $\left(^{\circ}\right)$} \\
\hline 1 & Slack & 1.05 & 0 \\
2 & PQ & 0.9 & -3.88 \\
3 & PV & 1.01 & -0.97 \\
4 & PQ & 0.87 & -4.86 \\
5 & PV & 0.88 & -4.54 \\
6 & PV & 0.89 & -4.26 \\
7 & PQ & 0.94 & -2.8 \\
\hline
\end{tabular}

\section{NUMERICAL MODEL OF STATCOM}

\subsection{Description of STATCOM:}

The static synchronous compensator STATCOM is one of FACTS derivates family, it us the forcing electronic power commutation (GTO, IGBT or IGCT). A STATCOM is a controlled reactive power source and improve the transient stability of systems. It provides voltage support by generating or absorbing reactive power at the point of common coupling without the need of large external or capacitor banks. The basic voltage source converter scheme is shown in Figure 4 [11].

\subsection{System of equations to determine bus voltages:}

3.2.1. Gauss-Seidel iterative method (GS) [1], [5], [6] and [2]

$$
V_{i}=\frac{1}{Y_{i i}}\left(\frac{\left(P_{i}-j Q_{i}\right)}{V_{i}^{*}}-\sum_{k=1, k \neq i}^{n} Y_{i k} V_{k}\right) \quad i=1,2, \ldots \ldots . ., \text { n et } i \neq s
$$


Where the active and reactive power each bus with indice i take the following form:

$$
\begin{aligned}
& P_{i}=\sum_{k=1}^{n}\left|Y_{i k}\right|\left|V_{i}\right|\left|V_{k}\right| \cos \left(\delta_{k}-\delta_{i}+\delta_{i k}\right) \\
& Q_{i}=\sum_{k=1}^{n}\left|Y_{i k}\right|\left|V_{i}\right|\left|V_{k}\right| \sin \left(\delta_{k}-\delta_{i}+\delta_{i k}\right)
\end{aligned}
$$

Since the voltage at the buses must be maintained within certain specified statutory limit, the voltage bound constraint limit at bus $\mathrm{i}$ is then defined by Equation (3):

$$
V_{i(\min )} \leq V_{i} \leq V_{i(\max )}
$$

Where Vi (min) and Vi (max) are minimum and maximum values of voltage at bus i.

The reactive power supply constraint at bus i is specified by Equation (4):

$$
Q_{g i(\min )} \leq Q_{g i} \leq Q_{g i(\max )}
$$

Where Qgi (min) and Qgi (max) are minimum and maximum values of reactive power supply at bus i

If the constraint defined by Equation (4) is not satisfied, Qgi is set to Qgi (max) if Qgi is greater than Qgi $(\max )$, and it is set to Qgi (min) if Qgi is less Qgi (max) and the constraint that voltage at bus $i$ is fixed must be released [8]. When STATCOM is shunt-connected at bus i in Figure 1 and it is treated as VAr source, the power equations writing as following:

$$
\begin{aligned}
& P_{i}=P_{g i}+P_{S T C i}-P_{l i} \\
& Q_{i}=Q_{g i}-Q_{S T C i}-Q_{l i}
\end{aligned}
$$

Where $\mathrm{P}_{\text {STCi }}$ STATCOM real power at bus i, $\mathrm{Q}_{\text {STCi }}$ STATCOM reactive power at bus i.

Equations (5) and (6) represent a case where STATCOM injects VAr into the system at bus i and for VAr absorption, the signs of $\mathrm{P}_{\mathrm{STCi}}$ and $\mathrm{Q}_{\mathrm{STCi}}$ become reversed.

Due to the non-linearity of algebraic Equations (5) and (6) describing the power flow, their solution is usually based on an iterative technique. Hence, the method of solution adopted in this work for power flow Equations (5) and (6) with a shunt-connected STATCOM at bus i is Newton-Raphson iterative method and it was adopted because of its faster rate of convergence and accuracy when compared with other methods of solution for non-linear power flow equations such as Gauss-Seidel method [1], [7].

\subsection{Mathematical model of power flow with STATCOM}

The Thevenin's equivalent circuit of the fundamental frequency operation of the switched mode voltage source inverter STATCOM and its transformer is shown in Figure 4 [8] and [9].

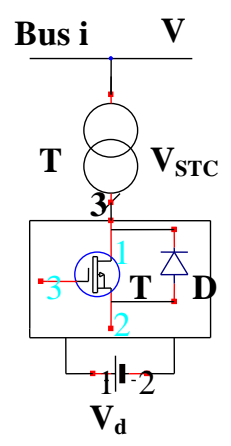

(a)

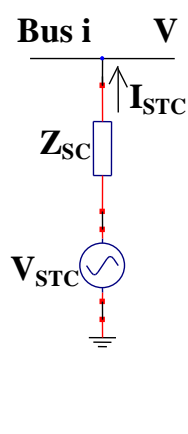

(b)

Figure 4. (a) Basic schematic diagram; (b) equivalent circuit [2] 
From Figure 4, we obtain Equation (8):

$$
V_{S T C}=V_{i}+Z_{S C} I_{S T C}
$$

Where $\mathrm{V}_{\mathrm{STC}}$ - Statcom voltage, $\mathrm{I}_{\mathrm{STC}}$ - Statcom current, $\mathrm{Z}_{\mathrm{SC}}$ - Transformers impedance. The voltage injection bound constraint of STATCOM is given by Equation (9) [12].

$$
V_{S T C(\min )} \leq V_{S T C} \leq V_{S T C(\max )}
$$

Where $\mathrm{V}_{\text {STC }}(\min )$ and $\mathrm{V}_{\text {STC }}(\max )$ - are the Statcom's minimum and maximum voltages.

Equation (8) is transformed into a power expression for STATCOM and power injected into bus i by Equations (10) and (11) respectively:

$$
\begin{aligned}
& S_{S T C}=V_{S T C} I_{S T C}^{*}=V_{S T C} V_{S T C}^{*} Y_{S C}^{*}-V_{S T C} Y_{S C}^{*} V_{i} \\
& S_{i}=V_{i} I_{S T C}^{*}=V_{i} V_{i}^{*} Y_{S C}^{*}-V_{i} Y_{S C}^{*} V_{S T C}^{*}
\end{aligned}
$$

Where $\mathrm{S}_{\mathrm{STC}}$ - STATCOM injected apparent power, $\mathrm{I}_{\mathrm{STC}}^{*}$ - complex conjugate of STATCOM current, $\mathrm{V}^{*}{ }_{\text {STC }}$ - complex conjugate of STATCOM voltage, $\mathrm{Y}_{\text {SC }}^{*}$ - complex conjugate of short-circuit admittance The bus i and STATCOM voltages in rectangular coordinates system are expressed as Equations (12) and (13) respectively:

$$
\begin{aligned}
& V_{i}=e_{i}+j f_{i} \\
& V_{S T C}=e_{S T C}+j f_{S T C}
\end{aligned}
$$

Where $e_{i}$ - real component of bus $i$ voltage, $f_{i}$ - imaginary component of bus $i$ voltage, $e_{S T C}-$ real component of STATCOM voltage, $\mathrm{f}_{\mathrm{STC}}$ - imaginary component of STATCOM voltage.

The STATCOM's voltage magnitude and angle are expressed as Equations (14) and (15) respectively:

$$
\begin{aligned}
& \left|V_{S T C}\right|=\left(e_{S T C}^{2}+f_{S T C}^{2}\right)^{\frac{1}{2}} \\
& \delta_{S T C}=\tan ^{-1}\left(\frac{f_{S T C}}{e_{S T C}}\right)
\end{aligned}
$$

The active and reactive power components for the STATCOM and bus $i$ on the basis of Equations (10) to (15) are respectively expressed by Equations (16) to (19):

$$
\begin{aligned}
& P_{S T C}=G_{S C}\left\{\left(e_{S T C}^{2}+f_{S T C}^{2}\right)-\left(e_{S T C} e_{i}+f_{S T C} f_{i}\right)\right\}+B_{S C}\left(e_{S T C} f_{i}-e_{S T C} f_{i}\right) \\
& Q_{S T C}=G_{S C}\left(e_{S T C} f_{i}-f_{S T C} e_{i}\right)+B_{S C}\left\{\left(e_{S T C} e_{i}+f_{S T C} f_{i}\right)-\left(e_{S T C}^{2}+f_{S T C}^{2}\right)\right\} \\
& P_{i}=G_{S C}\left\{\left(e_{i}^{2}+f_{i}^{2}\right)-\left(e_{i} e_{S T C}+f_{i} f_{S T C}\right)\right\}+B_{S C}\left(e_{i} f_{S T C}-e_{i} f_{S T C}\right) \\
& Q_{i}=G_{S C}\left(e_{i} f_{S T C}-f_{i} e_{S T C}\right)+B_{S C}\left\{\left(e_{i} e_{S T C}+f_{i} f_{S T C}\right)-\left(e_{i}^{2}+f_{i}^{2}\right)\right\}
\end{aligned}
$$

Where $\mathrm{P}_{\mathrm{STC}}$ - STATCOM real power, $\mathrm{Q}_{\mathrm{STC}}$ - STATCOM reactive power, $\mathrm{G}_{\mathrm{SC}}$ - short-circuit conductance, $\mathrm{B}_{\mathrm{SC}}-$ short-circuit susceptance

The Newton-Raphson set of linearized equations for power flow Equations (10), (11), (16) and (17) obtained taken into consideration the modeling of shunt-connected STATCOM at bus $\mathrm{i}$ is given by Equation (20) [6], [2]. 


$$
\left[\begin{array}{l}
\Delta P_{i} \\
\Delta Q_{i} \\
\Delta P_{S T C} \\
\Delta Q_{S T C}
\end{array}\right]=\left[\begin{array}{llll}
\frac{\partial P_{i}}{\partial e_{i}} & \frac{\partial P_{i}}{\partial f_{i}} & \frac{\partial P_{i}}{\partial e_{S T C}} & \frac{\partial P_{i}}{\partial f_{S T C}} \\
\frac{\partial Q_{i}}{\partial e_{i}} & \frac{\partial Q_{i}}{\partial f_{i}} & \frac{\partial Q_{i}}{\partial e_{S T C}} & \frac{\partial Q_{i}}{\partial f_{S T C}} \\
\frac{\partial P_{S T C}}{\partial e_{i}} & \frac{\partial P_{S T C}}{\partial f_{i}} & \frac{\partial P_{S T C}}{\partial e_{S T C}} & \frac{\partial P_{S T C}}{\partial f_{S T C}} \\
\frac{\partial Q_{S T C}}{\partial e_{i}} & \frac{\partial Q_{S T C}}{\partial f_{i}} & \frac{\partial Q_{S T C}}{\partial e_{S T C}} & \frac{\partial Q_{S T C}}{\partial f_{S T C}}
\end{array}\right]\left[\begin{array}{l}
\Delta e_{i} \\
\Delta f_{i} \\
\Delta e_{S T C} \\
\Delta f_{S T C}
\end{array}\right]
$$

Where the partial derivatives of the Jacobian matrix are defined on the basis of expression (21).

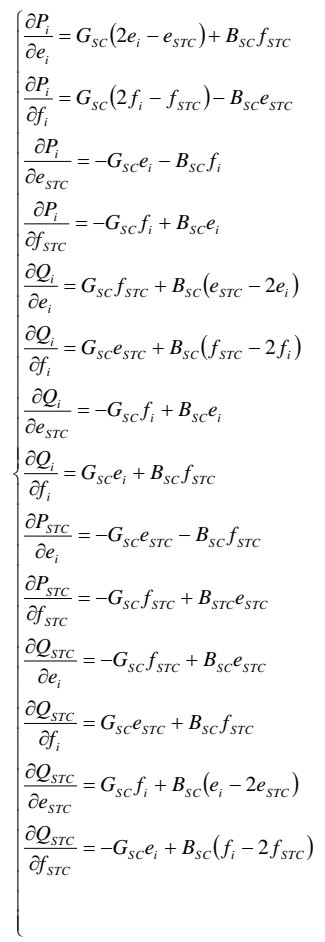

\subsection{Results of simulation and discussion} the system

In the Table 7 below is given the possible STATCOM location in buses and shown their impact on

Table 7. Results of STATCOM Connected to the Bus 2

\begin{tabular}{llll}
\hline Bus & Type & \multicolumn{1}{c}{ V pu } & Angle $\left(^{\circ}\right)$ \\
\hline 1 & 1 & 1.05 & 0 \\
2 & 2 & 1 & -7.07 \\
3 & 3 & 1.03 & -1.81 \\
4 & 3 & 0.97 & -7.8 \\
5 & 2 & 0.97 & -7.53 \\
6 & 2 & 0.98 & -7.29 \\
7 & 3 & 1.01 & -5.23 \\
\hline
\end{tabular}

The voltage profile before and after STATCOM connected are shown in the Figure 5, it demonstrates the voltage magnitude increased for the bus 2 at 0.90 (value out limit $[0,95 ; 1,05 \mathrm{pu}]$ ) to $1 \mathrm{pu}$, bus 4 at 0.87 to $0.97 \mathrm{pu}$, the bus 5 at 0.88 to $0.97 \mathrm{pu}$, the bus 6 at 0.89 to $0.98 \mathrm{pu}$, the bus 7 at 0.94 to $1.01 \mathrm{pu}$ and the bus 3 improved at 1.01 to $1.03 \mathrm{pu}$.

The voltage angle before and after STATCOM connected are shown in the Figure 6, it demonstrates the voltage angle increased for the bus 2 at -3.88 to -7.07 degree, bus 3 at -0.97 to- 1.81 degree, the bus 4 at -4.86 to -7.8 degree, the bus 5 at -4.54 to -7.53 degree, the bus 6 at -4.26 to -7.29 degree and the bus 7 at -4.03 to -5.23 degree

Table 8 shows the total active power loss. 


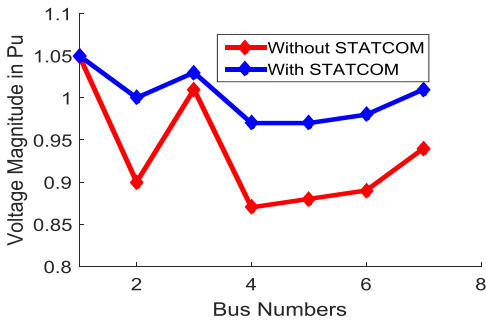

Figure 5. Curve of Voltage magnitude in pu

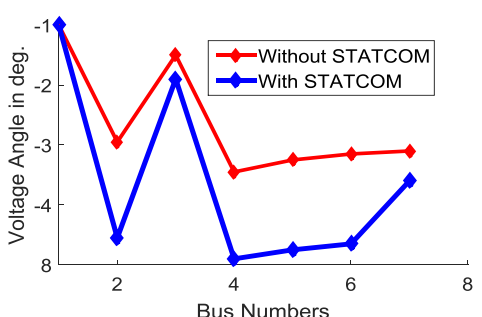

Figure 6. Curve of Voltage Angle in degree

Table 8. Total Active Power Loss

\begin{tabular}{lc}
\hline \multicolumn{2}{c}{ Total active power loss } \\
\hline Without STATCOM & 119 \\
With STATCOM & 88.2 \\
\hline
\end{tabular}

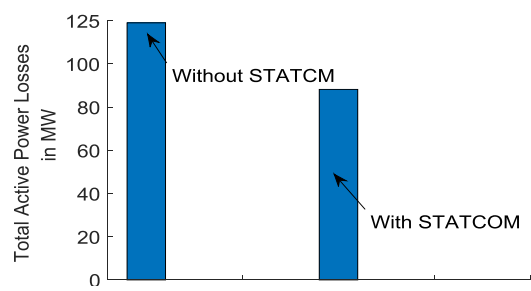

Figure 7. Curve of active power loss without with STATCOM

From the above Figure 7, there was a reduction in total active power loss from 119 MW to 88.2 MW, thereby improving the active power transmission lines. These results show that the STATCOM has the capability to improve the voltage at buses and reduce active power loss on the power system.

Table 9 shows the total reactive power loss.

Table 9. Total reactive power loss

\begin{tabular}{ll}
\hline \multicolumn{2}{c}{ Total reactive power loss } \\
\hline Without STATCOM & 158 \\
With STATCOM & 117.2 \\
\hline
\end{tabular}

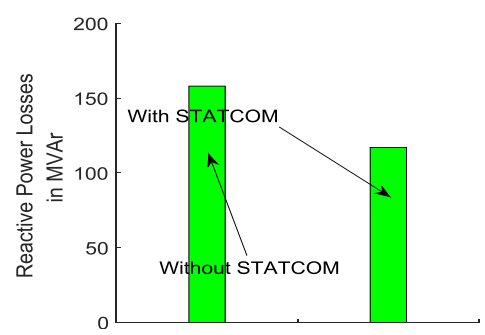

Figure 8. Curve of reactive power loss without and with STATCOM

From the above Figure 8, there was a reduction in total reactive power loss from $158 \mathrm{MVAr}$ to 117.2 MVAr, thereby improving the active power transmission lines. These results show that the STATCOM has the capability to improve the voltage at buses and reduce reactive power loss on the power system [4]. 


\section{CONCLUSION}

The simulation of the STATCOM on the Matlab and PSS/E Simulator using the NR method enabled us to see the voltage profile and the lines power mismatches. It should be noted that the STATCOM is in suitable to our predetermined goals, since it responds to all the problems related to the variation of loads and frequencies.

The power losses compared to the NR method without STATCOM are greater than with the STATCOM. The voltage of weakest buses is improved after insertion of the smart device (STATCOM) to $1 \mathrm{pu}$ and greater in stability limit [12].

In the end the expected disturbances of the network in the horizon 2030 were attenuated by installation of a FACTS system that is able to supply or absorb reactive power and to maintain the voltage to 1 pu.The completion of one research project opens the way to work in many other related areas. The following areas are identified for future work:

The load flow study can be done on larger interconnected power system like IEEE 14, IEE 30, and IEE 118 bus and even larger.

UPFC, IPFC and other FACTS controller can also be incorporated along the STATCOM and their effect on the system can be studied [11], [10] and [5].

Optimal location of STATCOM can be found out using Genetic Algorithm and fuzzy logic.

Economic Assessment of FACTS devices against other methods can be studied.

\section{REFERENCES}

[1] Jagpreet Singh, "Comparison of Newton-Raphson and Gauss-Seidel Load Flow Solution Techniques in Distributed Transmission and Generation Electricity Networks", International Journal of Advance Electrical and Electronics Engineering, pp. 17-25, 2016.

[2] Arshdeep Kaur Kailay, "Identification of best Load Flow Calculation Method for IEEE-30 BUS System using MATLAB", International Journal of Electrical and Electronics Research, vol. 3, pp.155-161, Sept 2015.

[3] P. S. Bhowmik, "Power Perturbation Method for Power Flow Analysis", International Journal of Automation and Power Engineering, pp.1-5, April 2012.

[4] Lakshmi M, et al., "Optimal Reactive Power Dipatch Using Crow Search Algorithm", International Journal of Electrical and Computer Engineering, vol. 8, pp. 1423-1431, Jun. 2018.

[5] John J. Paserba, et al., "FACTS Controllers Benefit AC Transmission System", (Mitsubishi Electric Power Products. Inc. Warrendale, Pennsylvania, USA, Gannon University 2007).

[6] Dr. H. V. Ramakrishna et al., "Effect of Acceleration Factor in Gauss Seidel Method on Load Flow Studies", International Journal for Research in Emerging Science and Technology, vol. 2, pp.1-8, May 2015.

[7] Arshdeep Kaur Kailay, et al., "FACTS based Power System Optimization by using Newton Raphson Technique", International Journal of Emerging Research in Management \&Technology, vol. 5, pp. 1-7, January 2016.

[8] John Wiley, et al., "FACTS, Modeling and Simulation in Powers Networks", (The Atrium, Southern Gate, Chichester, West Sussex PO19 8SQ, England 2004).

[9] Ahmed Zubair, et al., "Optimal Planning of Standalone Solar - Wind - Diesel for Coastal Area of Bangladesh", International Journal of Electrical and Computer Engineering, vol. 2, pp.731-738, 2012.

[10] Oyedoja, et al., "Modeling and Simulation Study of the use of Static VAr Compensator (SVC) for Voltage Control in Nigeria Transmission Network", International Journal of Engineering and Applied Sciences, vol. 5, Oct. 2014.

[11] Enrique Acha, et al., "FACTS Modeling and Simulation in Power Networks", John Wiley and Sons, LTD, 2004.

[12] Jean Pierre, "Plan Directeur de Production et Transport de l'énergie électrique en Mauritanie entre 2011-2030", GOPA-International Energy Consultants GmbH Leopoldsweg2, 61348 Bad Homburg, Allemagne, 2011.

\section{BIOGRAPHIES OF AUTHORS}

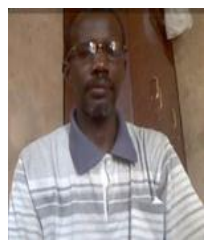

Eng. Ethmane Isselem Arbih was born in Tidjikja, Mauritania, in 1966.He received Master of Sciences degree in electrical systems and networks from Ukraina-Vinnitsa state university in 1994 .He teach in secondary technical school in Nouadhibou -Mauritanian city since 12 years. Currently work in doctorate thesis. His current research interests include Electric Network, Power Systems and Energy Efficiency and automatic control. Author of one publication.

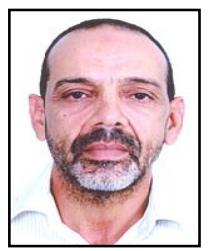

Prof. Mohamed Maaroufi was born in Marrakech, Morocco, in 1955. He received the Engineer Diploma from the Mohammedia School of Engineers (MSI), University Mohammed V, Rabat, Morocco in 1979 and the PhD from the "Université de Liege", Liege, Belgium in 1990. He joined the Electrical Engineering Department of MSI, where is currently Professor and Researcher. His current research interests include Electric Network, Smart Grid, Renewable Energy (mainly PV and Wind), Electric Drives, Power Systems and Energy Efficiency. The Scientific Research gives 08 theses and 90 papers in International Conferences and Journals. 


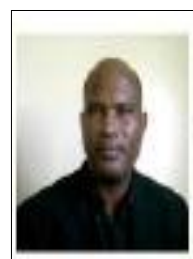

Prof. Abdel Kader Mahmoud was born in Aleg, Mauritania in 1960. He received his Master degree of Sciences in power stations in 1988 and his $\mathrm{PhD}$ degree in electrical engineering from the Technical University of Tashkent in Uzbekistan, in 1991. Then he received his second doctorate degree in renewable energy from the University of Cheikh anta Diop (UCAD), Dakar, Senegal, in 2008. Currently he is in charge of the Applied Research Laboratory of Renewable Energy (LRAER). He is the author and co-author of more than 30 scientific papers.

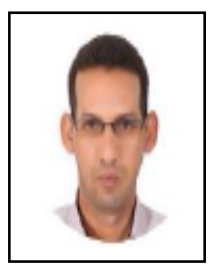

Ing. Ahmed Yahfedhou was born in Boutilimitt, Mauritania in 1978.He received his Master degree in Solar Energy, Materials and Systems from College of Sciences and Technics, Dakar, Senegal, UCAD in the year 2010. He is working on his doctorate thesis at Cheikh Anta DIOP, University Dakar, Senegal. Author of more 4 publications yahevdhouah@yahoo.fr 